\title{
EDUCAÇÃO E POBREZA: UMA CONSTRUÇÃO HISTÓRICO-SOCIAL
}

\author{
EDUCATION AND POVERTY: A HITOTICAL-SOCIAL CONSTRUCTION
}

EDUCACIÓN Y POBREZA: UNA CONSTRUCCIÓN HISTÓRICO-SOCIAL

\author{
Joanderson de Oliveira Gomes ${ }^{*}$ - (D)
}

${ }^{1}$ Mestrando em Educação pela Universidade Federal da Paraíba (UFPB). Especialista em Educação e Políticas Públicas pela Universidade Estadual da Paraíba (UEPB). Pedagogo pela Universidade Federal da Paraíba (UFPB). Paraíba, Brasil.*Autor correspondente: joandersonooliveira@gmail.com.

Recebido: 21/04/2021 | Aprovado: 10/05/2021 | Publicado: 31/05/2021

Resumo: O presente artigo trata-se de um recorte do Trabalho de Conclusão de Curso de Especialização em Educação e Políticas Públicas intitulado "Construção histórico-social da pobreza: a escola e sua função social" e tem como finalidade compreender a relação entre educação e pobreza a partir da escola. Para tanto, analisou-se parte da literatura que trata da construção histórico-social da pobreza, assim como também se observou a relação entre pobreza e educação com base em artigos, livros, teses e dissertações que tratam da temática. Discutiu-se, portanto, a função social da escola com a propositura de uma educação emancipatória e transformadora da realidade, uma vez que persiste a existência da pobreza em nosso país, com efeitos diretos na vida de cada sujeito. A pobreza existe e não podemos ignorá-la, assim, é importante refletir sobre a escola que temos e os cidadãos que formamos, a fim de desnaturalizar a problemática e miminizar as desigualdades sociais. Além disso, o momento de escrita deste trabalho converge com o cenário pandêmico ocasionado pela Covid-19, que tem submetido as comunidades às condições de extrema vulnerabilidade social, econômica e de saúde pública. Por fim, a educação é o caminho para a formação do pensamento crítico e o desenvolvimento de políticas públicas que consideram a realidade local.

Palavras-chave: Educação. Pobreza. Desigualdade Social. Vulnerabilidade.

Abstract: This article is an excerpt from the Conclusion of the Specialization Course in Education and Public Policies entitled "Historical-social construction of poverty: the school and its social function" and aims to understand the relationship between education and poverty from school. For that, part of the literature that deals with the historical-social construction of poverty was analyzed, as well as the relationship between poverty and education was also observed based on articles, books, theses and dissertations that deal with the theme. Therefore, the school's social function was discussed with the proposition of an emancipatory and reality-transforming education, since the existence of poverty persists in our country, with direct effects on the life of each subject. Poverty exists and we cannot ignore it, so it is important to reflect on the school we have and the citizens we form, in order to denaturalize the problem and minimize social inequalities. In addition, the moment of writing this work converges with the pandemic scenario caused by Covid-19, which has subjected communities to conditions of extreme social, economic and public health vulnerability. Finally, education is the path to the formation of critical thinking and the development of public policies that consider the local reality.

Keywords: Education. Poverty. Social inequality. Vulnerability.

Resumen: Este artículo es un extracto de la Conclusión del Curso de Especialización en Educación y Políticas Públicas titulado "Construcción histórico-social de la pobreza: la escuela y su función social" y tiene como objetivo comprender la relación entre educación y pobreza desde la escuela. Para ello, se analizó parte de la literatura que trata sobre la construcción histórico-social de la pobreza, así como también se observó la relación entre pobreza y educación a partir de artículos, libros, tesis y disertaciones que abordan el tema. Por ello, se discutió la función social de la escuela con el planteamiento de una educación emancipadora que transforme la realidad, ya que la pobreza persiste en nuestro país, con efectos directos en la vida de cada individuo. La pobreza existe y no podemos ignorarla, por eso es importante reflexionar sobre la escuela que tenemos y los ciudadanos que formamos, para desnaturalizar el problema y minimizar las desigualdades sociales. Además, el momento de redactar este trabajo converge con el escenario pandémico provocado por el Covid-19, que ha sometido a las comunidades a condiciones de extrema vulnerabilidad social, económica y de salud pública. Finalmente, la educación es el camino para la formación del pensamiento crítico y el desarrollo de políticas públicas que consideren la realidad local.

Palabras clave: Educación. Pobreza. Desigualdad social. Vulnerabilidad. 


\section{INTRODUÇÃO}

O presente artigo trata-se de um recorte do Trabalho de Conclusão de Curso de Especialização em Educação e Políticas Públicas pela Universidade Estadual da Paraîba (UEPB) intitulado "Construção históricosocial da pobreza: A escola e sua função social”, ele tem por objetivo traçar, ainda que de forma breve uma reflexão acerca de pobreza e educação, na perspectiva de compreendê-la sob a propositura da construção histórico-social e dos possíveis entraves que a perpassam.

Não precisamos ir muito longe para nos depararmos com situações de pobreza em nosso país, em uma pequena volta por sua cidade certamente você irá se deparar com pessoas vivendo em estado de calamidade. É comum encontrarmos em nosso país pessoas desabrigadas, vivendo a céu aberto, durante o dia castigadas pelo sol, a noite cobertas pela lua. Para sujeitos em situação de vulnerabilidade social falta alimento, saúde, educação, se formos prosseguir a lista se tornará ainda maior.

Ao adentrarmos na discussão a respeito da Educação, Pobreza e Desigualdade Social inevitavelmente tocamos na esfera da vulnerabilidade social, e embora não pretenda me estender muito e de forma mais aprofundada nela, é pertinente que abordemos, mesmo que de forma sucinta o tema. Desse modo, contribuirá para um maior esclarecimento acerca de nossa discussão em um modo mais geral partindo assim para um recorte mais específico das demandas postas por este trabalho e aqui abordadas no decorrer de todo o texto.

O Índice de Vulnerabilidade Social - IVS (2015, p. 13), construído a partir de indicadores do Atlas do Desenvolvimento Humano - ADH, no Brasil, entende vulnerabilidade social na perspectiva do "acesso, à ausência ou à insuficiência", no tocante "as falhas de oferta de bens e serviços públicos no território nacional". Além disso, Silva \& Rapoport (2013, p. 3) afirmam quem embora as discussões da pobreza perpassem a dimensão da vulnerabilidade social, não é ela que a define, segundo as autoras "vulnerabilidade caracteriza-se também pela impossibilidade de modificar a condição atual em que se encontra".

A nomenclatura pobreza, nesse sentido vem perdendo sua capacidade de dar conta da ampla situação vivenciada por sujeitos em situações de pobreza, não se limitando apenas a falta de recursos monetários, mas também e consequentemente o reflexo que isso tem no tocante a falta de saúde, educação, moradia, a viverem uma vida justa e digna, que em tese estão asseguradas em nossa Constituição Federal (BRASIL, 1988).

Desta forma, Prati, Couto \& Koller (2009, p. 404) apud (Silva \& Rapoport 2013, p. 3) afirmam que "vulnerabilidade social é uma denominação usada para caracterizar famílias expostas a fatores de risco", riscos estes que podem ser "de natureza pessoal, social ou ambiental”. Além disso, Carmo \& Guizardi (2017, p. 5) definem o conceito de vulnerabilidade social como aquele que necessita de ajuda, nas palavras das autoras "diz do estado de ser/estar em perigo ou exposto a potenciais danos em razão de uma fragilidade atrelada à existência individual". Dito de outro modo, está em condição de vulnerabilidade social é está à margem do exercício da cidadania, ao menos da cidadania que em tese prevê garantias para o viver em sociedade de forma digna. 
Adentrar na discussão sobre educação e pobreza é um dos desafios desse trabalho, começando por um dos princípios fundamentais de nossa Constituição, que é o da "dignidade da pessoa humana". Dignidade esta que tem faltado a muitos, e nós não podemos nos esquecer disso. Assim, será tomado como ponto de partida a questão da pobreza enquanto construção histórico-social, ligada a interesses que acabam por gerir impactos enormes na vida dos sujeitos.

Cabe aqui ressaltar que este trabalho não está pautado em analisar perfis de sujeitos em situações de pobreza de forma específica. Não foi escolhido aqui um grupo de crianças, jovens ou adultos. De modo que no decorrer do texto fala-se de um ou outro ou mesmo de ambos, - ainda que seja de forma genérica. O foco, no entanto, está centrado na discussão sobre pobreza e educação, em sentido amplo. Compreender as nuances que perpassam a pobreza tomando por base a educação enquanto possibilidade de analisar do ponto de vista crítico.

O presente trabalho se justifica pela constatação da persistente existência da pobreza em nosso país, que tem efeito direto na vida de cada sujeito. Grosso modo, a pobreza existe, e não podemos ignorá-la. Dessa maneira, é importante oportunizar espaços de reflexão sobre a temática, na perspectiva da promoção de rupturas em visões estereotipadas nos conceitos da pobreza e na visão moralizadora que se tem sobre ela.

\section{PERCURSO METODOLÓGICO}

Para a feitura deste trabalho foram analisados textos, artigos, livros que abordassem o tema educação e pobreza, para coleta dos arquivos foram acessados as principais bibliotecas digitais, fez-se uso da Scientific Eletronic Library Online - SCIELO, e a Biblioteca Digital Brasileira de Teses e Dissertações - BDTD, para além das bibliotecas digitais, também foram utilizados aqui os módulos, livros e artigos que compõe o acervo do Curso de Aperfeiçoamento Educação, Pobreza e Desigualdade Social, disponibilizado na própria plataforma do curso da UFPB/Virtual.

Bello et al. (2012, p. 54) entendem pesquisa bibliográfica como a "revisão da literatura sobre as principais teorias que norteiam o trabalho científico". Tal revisão é o que se denomina de "levantamento bibliográfico ou revisão bibliográfica, a qual pode ser realizada em livros, periódicos, artigo de jornais, sites da Internet entre outras fontes".

Ainda sobre a pesquisa bibliográfica Bello et al. (2012, p. 54) afirmam que este tipo de pesquisa proporciona melhor aprendizado sobre determinada área, proporcionando "um trabalho minucioso em busca do conhecimento e base fundamental para o todo de uma pesquisa".

Nesse sentido, buscou-se perfazer os caminhos postos por Medeiros (2012), quando recomenda o uso de métodos científicos e reflexão sistemática. Ainda no tocante à pesquisa bibliográfica o autor nos alerta que ela "não se resume na busca da verdade; aprofunda-se na procura de resposta para todos os porquês envolvidos na e pela pesquisa" (Medeiros, 2012, p. 38). 
A escolha dos textos - leia-se livros, artigos, teses, dissertações - ocorreu a partir da temática educação e pobreza, logo os artigos que versavam sobre essa temática tinham seus resumos lidos e aqueles que mais se aproximavam do objetivo deste estudo foram selecionados.

$\mathrm{Na}$ Scielo ao digitar as palavras educação e pobreza na ferramenta de busca, obteve-se um total de 173 artigos em português, selecionou-se os 5 primeiros, seus resumos foram lidos e a partir dos resumos foi-se elencando aqueles que acredito que podem contribuir da melhor forma nessa pesquisa. Na BDTD ao buscar pelas palavras educação e pobreza na ferramenta de busca obteve-se um total de 853 resultados, também foram lidos os cinco primeiros resumos das cinco teses e dissertações e optou-se por trabalhar apenas com Duarte (2012), justamente pelo enfoque e destaque trazido pela autora tanto no resumo quanto no título do trabalho ao focalizar um estudo específico sobre educação e pobreza. No trabalho de Duarte (2012) ouve de fato uma confluência de ideias, sua tese versava exatamente sobre o tema de investigação, educação e pobreza, nesse sentido, desconsiderou-se as demais a fim de realizar uma leitura mais aprofundada da tese de Duarte (2012).

A tese de Duarte (2012), tem por título a "Política Social: um estudo sobre educação e pobreza", e foi apresentada ao Programa de Pós-Graduação em Política Social da Universidade de Brasília. A autora busca fazer uma análise da relação entre educação formal e a população em situação de pobreza, a partir das escolas públicas do Distrito Federal.

Por meio da pesquisa desenvolvida foi possível identificar que existem avanços na perspectiva da diversidade nas escolas investigadas, constatou-se a existência de projetos políticos pedagógicos que contemplavam as temáticas de direitos humanos, meio ambiente, raça e orientação sexual, no entanto as questões de gênero e da pobreza permanecem invisíveis, este último foi ao qual mais me detive. O que chamou a atenção neste estudo foi a importância dada a esta temática frente a realidade encontrada em nosso país. Conforme Duarte (2012, p. 33), podemos constatar em sua pesquisa que “o Brasil não é um país pobre, mas um país com muitos pobres". Demonstrando uma diversidade discente que exige do professor um olhar sensível e cuidadoso dentro e fora da sala de aula.

\section{RESULTADOS E DISCUSSÃO}

\subsection{Breve reflexão: a pobreza enquanto processo de construção histórico-social.}

Talvez você se pergunte de quando se data a pobreza. Popularmente falando, poderíamos dizer "desde que o mundo é mundo", mas isso não nos basta, então recorremos a Schwartzman (2004, p. 14) que afirma que "a pobreza e a desigualdade são tão antigas quanto a humanidade e sempre vieram acompanhadas de fortes sentimentos morais". Mas afinal o que significa ser pobre? O que nos diz a religião sobre isso? O que o Estado entende por pobreza? Para responder a algumas dessas perguntas Guimarães (2016, p. 1) nos traz algumas afirmações, segundo o autor "a Igreja concebeu o pauperismo como determinação divina; o Estado entendeu a pobreza como conjuntura social para intervenção de leis”. 
Para Rocha (2003, p. 9), "Pobreza é um fenômeno complexo, podendo ser definido de forma genérica como a situação na qual as necessidades não são atendidas de forma adequada". Dito de outro modo, ser pobre significa não ter acesso aos meios para viver adequadamente no grupo social em que se vive, fazendo uso de direitos básicos, como moradia, saúde e educação.

Schwartzman (2004, p. 13) ao discorrer sobre "as causas da pobreza", nos leva a refletir sobre isso e nos indaga a respeito da origem da pobreza, e nos conta que ainda quando era estudante de Ciências Sociais, aprendeu que as raízes da pobreza estariam fincadas não em motivos "individuais, mas estruturais". Com a pretensão de estimular a consciência de classe, o autor nos conta que "falar com os pobres não adiantava muito", muitos se sentiam ofendidos ao ouvirem sobre sua situação de vulnerabilidade social, afinal eles eram pobres sim, "mas tinha orgulho de seu barraco limpo e arrumado".

Tal realidade relatada por Schwartzman (2004), ainda se perpetua nos dias atuais, ao abordarmos a temática da pobreza e tentar estabelecer uma relação crítica a respeito do tema, com a perspectiva da consciência do estado em que se vive, muitas pessoas sentem-se ofendidas, não se reconhecem nem se percebem enquanto pobres. Tal pensamento se funda em uma visão moralizante de pobreza.

Nesse sentido, Arroyo (2015, p. 15) alerta que é preciso superarmos visões moralizantes da pobreza, pois assim "estaremos abertos a reconhecer que a pobreza e as desigualdades sociais [...], estão associadas ao padrão de poder-dominação-subalternização vigente na sociedade”.

Quem seriam então os pobres? Ainda nas palavras de Arroyo (2015, p. 16), “os/as pobres são os/as sem-terra, sem-teto, sem-trabalho, sem-renda, sem-escola, sem-saúde, cujas vidas se encontram nos limites da sobrevivência". Grosso modo o autor nos mostra que a pobreza é uma questão social, e ao passarmos a vê-la dessa forma, poderemos perceber também que se trata ainda de uma questão política, entendê-la como um problema do Estado, e sendo assim, ainda nas palavras de Arroyo (2015), passaremos a "exigir as políticas de Estado capazes de alterar essa realidade".

O fato é que não podemos desconsiderar a historicidade da pobreza. As concepções e o entendimento sobre ser pobre foram mudando no decorrer do tempo, sempre atendendo a uma determinada demanda social, isso de forma proposital. Os discursos a respeito dos pobres iam - e em certa medida ainda vão -, trazendo uma naturalidade a pobreza que não lhe condiz efetivamente.

Schwartzman (2004, p. 14) nos fala que ao longo do processo histórico a pobreza vai sendo entendida de diversas formas. Segundo o autor "em todas as sociedades sempre se reconheceu a virtude de ajudar os pobres", e nesse sentido Schwartzman nos fala do valor conferido a caridade com relação a pobreza, porém não qualquer pobre. “A questão era, então, quem, entre os necessitados, deveria receber ajuda?”, como então a caridade seria administrada?

Para responder a questões dessa natureza inevitavelmente era preciso classificar as pessoas. Os parentes teriam prioridade, depois os vizinhos e concidadãos, ainda segundo Schwartzman (2004) ficavam de fora da lista 
“os desconhecidos e estrangeiros". Para nos situarmos dentro do período histórico, o autor se refere ao século XIX. Essa forma de organização era uma forma de classificar quem merecia ou não.

Uma outra forma trazida pelo autor dizia respeito a "pobreza involuntária - e por isso digna - dos órfãos, doentes e viúvas". Do outro lado estaria a "pobreza voluntária - e por isso indigna - das pessoas saudáveis que não queriam trabalhar para se manter”.

A pobreza era entendida como uma condição natural das pessoas, que, em situações especiais, ficavam desvalidas e merecedoras de amparo; a mendicância, por outro lado, era uma deformação de caráter e, por isso, indigna de apoio e ajuda. (Schwartzman, 2004, p. 15)

Reforçando o que já foi dito por Schwartzman (2004), Guimarães (2016, p. 7) afirma que "a figura do pobre (pessoa desprovida de) sempre existiu desde os primórdios das civilizações”. Comecemos com o discurso da Igreja, que durante muito tempo afirmou que ser pobre era algo relacionado à vontade divina, - "você é assim porque Deus quis, aceite" -, ainda conforme Guimarães (2016), os principais combatedores (e mantenedores) da pobreza foram a Igreja Católica e o Estado. As medidas tomadas eram muito mais de caráter assistencialistas, que embora importantes e necessárias para aqueles que passam por privações, não traziam mudanças de quadro, apenas suprimiam uma necessidade do momento.

Isso ocasionou um processo de naturalização da pobreza, retirando a criticidade do pobre sobre sua real condição, ainda imputando aos pobres a culpa por sua situação de vulnerabilidade social. Muitas vezes vistos como preguiçosos, desocupados, ou afirmam que eles são pobres porque querem. Tais pensamentos se fundam na total descontextualização do cotidiano dessas pessoas. O que se faz nesse caso é reduzir a dimensão da pobreza a uma visão moral, Arroyo (2015) afirma que:

Quando se imputa aos/às pobres a sua condição de pobreza e considera-se que são carentes de valores, passa-se a entrever apenas uma solução: educa-los/as nos valores do trabalho, da dedicação e da perseverança, desde a infância. Nesse contexto, a tarefa da escola diante de milhões de crianças e adolescentes na extrema pobreza seria de moralizá-los/as nesses valores, que eles/as supostamente não recebem das famílias e dos coletivos empobrecidos. A escolarização, então, seria somente um antidoto contra a pobreza ao moralizar as infâncias e adolescências pobres (Arroyo, 2015, p. 10).

Tal processo de escolarização se esvazia de criticidade, não reflete sobre as condições da pobreza enquanto fenômeno social, tampouco como processo que foi construído historicamente. Santos (2017, p. 244) afirma que "a escola pública, que deveria ser igual para todos, acaba por reproduzir e reforçar as desigualdades econômicas, sociais e políticas presentes em nossa sociedade”. É necessário que a escola discuta essas questões, e supere o status quo que tem se estabelecido, ao invés de agir apenas como aparelho de manutenção dele.

A permanência desse estado de inércia sobre a pobreza parece ser entendida como algo melhor, para efeito mais imediato, Freire (2019, p. 32) aponta que o que se espera é que “[...] a situação concreta de injustiça não se constitua num 'percebido' claro para a consciência dos que a sofrem”. O que Freire vai defender então é a participação ativa do sujeito no campo social, para que assim ele possa "inserir-se no processo histórico, como sujeito" que age sobre o meio, o transformando. 
Dessa forma, Santos (2017, p. 245) afirma que "considera-los no centro do processo educativo acarreta reorganizar tempos, espaços, agrupamentos, conteúdos escolares". E em certa medida isso é algo novo para o espaço escolar, que historicamente foi incumbido de homogeneizar, remover as arestas, igualar todo mundo no mesmo nível, fazer com que todos "caibam no mesmo pote". Agora a escola precisa aprender a lidar com a diversidade.

O que não tem sido tarefa muito fácil, se antes todos eram vistos como iguais, agora é preciso considerar as subjetividades, tratar todos como iguais não é mais uma forma justa de se trabalhar. Tal fato tem trazido um certo insucesso para a escola, segundo Santos (2017, p. 245) “[...] esse insucesso acaba tendo rosto: crianças e jovens que fracassam na escola, em sua maioria, são pobres, negros, índios, camponeses, moradores de regiões menos favorecidas".

A condição de pobreza muitas vezes é confundida por preguiça de trabalhar, e medidas assistencialistas são vistas como acomodação para os que dela necessitam e fazem uso. Tal visão é extremamente preconceituosa. Muitas vezes ser pobre está ligado a uma vida de trabalho duro e de baixa remuneração, oportunizando aos sujeitos uma vida regada a diversas privações. Guimarães (2016, p. 2) elucida que a pobreza “tem se tornado sinônimo de ausência de virtudes individuais, promiscuidade, vadiagem, incompetência, preguiça, criminalidade e vagabundagem”.

Muitos de nossos/as jovens e adolescentes vivem no que Leite (2015) chamou de "limites da sobrevivência", suas condições de vida deixam amostra a grave desigualdade social que paira em nosso país. Ao falar em infâncias e adolescências, no plural, estamos falando de um mundo diverso onde alguns têm acesso a tudo e mais um pouco, boa saúde, educação, livros, internet, viagens, e a lista só cresce. Enquanto no lado oposto muitos acordam antes do sol surgir para ajudar os pais no sustento da casa. Trabalham o dia todo para ganhar quase nada, chegam à escola esgotados. Uns catam "Pokémon"” outros catam lata, papelão, pois disso depende sua existência.

Em matéria publicada no site das Organização das Nações Unidas - $\mathrm{ONU}^{3}$, novos dados nos são apresentados com relação ao trabalho infantil, frente a pandemia da Covid-194 , nos é feito um alerta após uma análise realizada pela Comissão Econômica para a América Latina e o Caribe - CEPAL e da Organização Internacional do Trabalho - OIT, (2020) segundo a análise "109 mil a 326 mil meninos, meninas e adolescentes poderiam entrar no mercado de trabalho, somando-se aos 10,5 milhões atualmente em situação de trabalho infantil".

\footnotetext{
2 Trata-se de um jogo eletrônico de realidade aumentada feito para smartphones. Fonte: Niantic, Inc.

${ }^{3}$ https:// nacoesunidas.org/crise-pode-lancar-ate-326-mil-criancas-ao-trabalho-infantil-na-america-latina-e-caribe/

4 A COVID-19 é uma doença causada pelo coronavírus, denominado SARS-CoV-2, que apresenta um espectro clínico variando de infecções assintomáticas a quadros graves. De acordo com a Organização Mundial de Saúde, a maioria (cerca de 80\%) dos pacientes com COVID-19 podem ser assintomáticos ou oligossintomáticos (poucos sintomas), e aproximadamente 20\% dos casos detectados requer atendimento hospitalar por apresentarem dificuldade respiratória, dos quais aproximadamente $5 \%$ podem necessitar de suporte ventilatório.

Fonte: https://coronavirus.saude.gov.br/sobre-a-doenca\#
} 
É dentro desses espaços de vivências que nossos jovens e nossas crianças constroem suas experiências de vida, e os das camadas populares de fato vivem nos limites da sobrevivência. A Constituição parece os ter esquecido, o Estado vai na mesma direção. Arroyo (2004) apud (Leite 2015, p. 13), nos alerta que "é necessário quebrar imagens que tendem a compreender as crianças e os/as jovens pelo que eles/as não são". Ao que Freire (2019) chamou de visão fatalista. O fato é que a pobreza vem se perpetuando na linha da história da humanidade, e mesmo que tenhamos tido alguns avanços na contemporaneidade, ainda temos muito o que melhorar na luta por melhores condições de vida.

$\mathrm{Na}$ esteira desse pensamento Leite (2015, p. 14) nos chama atenção para o fato de que "dentro de uma mesma cidade e amparadas pelas mesmas legislações e políticas, diferentes crianças e jovens não têm acesso aos mesmos direitos". E mesmo quando conseguem ter acesso, como é o caso da escola, isso ocorre de forma muito desigual, uma vez que as condições para o acesso e permanência no ambiente escolar são peculiares de cada sujeito.

O Estatuto da Criança e do Adolescente - ECA, por exemplo, a partir do seu Art. 53, do direito à educação, à cultura, ao esporte e ao lazer afirma que "a criança e o adolescente têm direito à educação, visando ao pleno desenvolvimento de sua pessoa, preparo para o exercício da cidadania e qualificação para o trabalho", (BRASIL, 1990). Entretanto sabemos que na prática isso nem sempre acontece. Um outro ponto preconizado pela ECA, ainda no Art. 53, "I - igualdade de condições para acesso e permanência na escola”, igualdade esta que ainda não conseguimos instaurar efetivamente na vivência prática de nossas escolas.

Arroyo (2015, p. 8) afirma que “a postura mais comum é ver a pobreza como carência e, consequentemente, os pobres como carentes". Desconsidera-se as privações das condições mais básicas, enfrentadas por esses sujeitos que o impedem de ter uma vida justa e digna.

Se olharmos nosso cenário atual, quando o mundo inteiro enfrenta a pandemia da Covid-19 perceberemos o agravamento que as pessoas em situação de vulnerabilidade social estão tendo que lidar. É certo que algumas medidas assistenciais tem sido tomadas, o governo lançou o auxílio emergencial ${ }^{5}$ visando trazer alguma renda para milhões de brasileiros que devido a pandemia ficaram com pouco ou nenhum sustento, entidades tem realizado campanhas na perspectiva de prover roupas, cobertores, comidas, enfim, medidas que de fato são urgentes e extremamente necessárias.

Entretanto tais medidas não trazem garantias de mudança duradoura e efetiva na realidade enfrentada por famílias que vivem no limite da sobrevivência. Podemos perceber que a Covid-19 nos coloca a prova com a nossa incapacidade de lidar com a pobreza e nesse sentido não podemos perder de vista a necessidade de questionar o poder público no que diz respeito aos direitos básicos fundamentais.

${ }^{5} \mathrm{O}$ Auxílio Emergencial é um benefício financeiro destinado aos trabalhadores informais, microempreendedores individuais (MEI), autônomos e desempregados, e tem por objetivo fornecer proteção emergencial no período de enfrentamento à crise causada pela pandemia do Coronavírus - COVID 19.

Fonte: https://auxilio.caixa.gov.br/\#/inicio 
Trisotto (2020, p. 1) destaca que "com a Covid-19, milhões de brasileiros serão submetidos à pobreza. São pessoas que não engrossavam essas estatísticas antes, mas serão, sim, afetadas pela queda abrupta, se não total, da renda". Diversas pessoas ficaram desempregadas, principalmente as pessoas de menor escolaridade, outras tantas que trabalham de forma autônoma estão impedidas de trabalharem e assim prover algum sustento.

O cenário todo é de incertezas. Os mais pobres e vulnerabilizados já estavam perdendo renda no cenário pré-crise do coronavírus - a extrema pobreza avançou 67\% entre 2014 e 2018 e a renda dos 5\% mais pobres caiu 39\%. A informalidade dominou o mercado de trabalho e já havia um processo de histerese - apesar da taxa de desemprego alta, mesmo as melhoras econômicas eram insuficientes para uma redução robusta do indicador (Trisotto, 2020, p. 1).

Como enfrentar uma pandemia sem ter o que comer? O que beber? Ou mesmo o que vestir? Milhões de brasileiros estão a mercê do povir, e na incerteza do como será. É preciso refletirmos sobre essas questões, pois concordo com Freire (2019, p. 72-73) quando afirma que "ao defendermos um permanente esforço de reflexão dos oprimidos sobre suas condições concretas, não estamos pretendendo um jogo divertido em nível puramente intelectual", pelo contrário, o que se espera é que a reflexão conduza a prática.

De modo geral as condições são distintas e algumas severas. Analisemos por exemplo o fato de que precisamos ficar em casa, para assim evitar a propagação do vírus da Covid-19, mas e quem vive das ruas e de lá tira seu sustento? A exemplo de uma senhora que em entrevista a um programa de tv afirmou que tinha comida para mais cinco dias e depois disso não saberia como iria ser. É sobre essas pessoas que esse trabalho busca refletir, que embora estejam sempre no espaço social em diversos momentos são tratados como invisíveis.

As medidas de assistência social são muito importantes e certamente tem ajudado muito aqueles que delas conseguiram ter acesso, no entanto nossa luta precisa ser maior, superando os muros da caridade e oportunizando aos sujeitos transformação social, autonomia.

\subsection{A relação entre educação e pobreza}

Educação e pobreza vêm caminhado lado a lado desde o início dos tempos. No limiar deste caminhar, existe quem defenda que a educação é condição necessária para a superação da pobreza, outros defendem que ela sozinha não dará conta de toda a complexidade que perpassa o trilhar dos caminhos do pauperismo.

Nas curvas criadas por esse caminhar entre educação e pobreza muito se discutiu sobre o acesso à educação, uma educação pensada para todos. Realidade ou utopia? Duarte (2012, p. 26) afirma que "a democratização do acesso à escola não veio acompanhada da permanência e sucesso escolar", havia - e ainda existe - muitos entraves que se colocam na relação entre educação e pobreza, a começar pelo ensino, pensado a partir da realidade das elites, o que acaba não indo ao encontro a realidade das camadas populares que vivem em situação de pobreza.

Ainda na esteira do pensamento de Duarte (2012) podemos perceber que a educação, grosso modo, passa a ser entendida como "mérito individual e não como direito social", logo o sujeito não consegue sair da pobreza mesmo tendo acesso à educação. A responsabilidade passa a ser sua, isso, claro e evidentemente dentro 
de uma lógica totalmente excludente que não toma por base a realidade daqueles que vivem nos limites da sobrevivência.

Partindo desse princípio temos uma educação desigual, onde pessoas com vivências distintas são postas a lidarem com cobranças (des)iguais. Dito de outro modo, espera-se que um aluno com poucos recursos, que não tem acesso a livros, computador, internet e o que mais se possa pensar de recursos existentes, tenha o mesmo progresso de um aluno que desde cedo viveu em um ambiente de privilégios sociais, desde o acesso a livros, cultura, teatro, entre outros.

Em linhas gerais a escola trás justamente um currículo que dialoga com a realidade das elites. Fica então a pergunta: que relação as camadas populares poderão fazer com esse currículo? A esse respeito Silva (2013, p. 45) afirma que a educação é afetada diretamente pela dinâmica da sociedade capitalista. Segundo o autor, ela (a educação) "gira em torno da dominação de classe, da dominação dos que detêm o controle da propriedade dos recursos materiais sobre aqueles que possuem apenas sua força de trabalho”. Ou seja, essa lógica de organização tem afetado diretamente outras esferas do campo social, como a educação por exemplo.

Nesse sentido, Rocha (2003, p. 184) destaca que "a redução da pobreza absoluta e da desigualdade de renda no Brasil passa, necessariamente, por mudanças estruturais no sistema educacional”, tais mudanças devem encontrar meios de garantir não apenas o acesso, mas a permanência do aluno na escola.

Construir currículos que garantam o direito dos/as alunos/as pobres a entenderem sua condição de pobreza não é tarefa simples, uma vez que os conhecimentos dos currículos continuam cultuando um conhecimento abstrato e conceitual que ignora, sobretudo, os sujeitos sociais e suas experiências. Relacionar currículo e pobreza exigirá aproximar os conhecimentos daquele com as experiências sociais da pobreza, com os sujeitos individuais e coletivos que as vivenciam; demandará colocar em diálogo suas indagações sobre a pobreza, suas causas, sua produção histórica com as indagações históricas que os conhecimentos dos currículos condensam (Arroyo, 2015, p. 20).

A escola é uma instituição social que tem a propositura de trazer o progresso aos sujeitos, Leite (2015, p. 15) nos chama a atenção para os processos históricos que estão ligados diretamente a discussão que se segue nos parágrafos anteriores, a saber, a escola como ferramenta de reprodução das desigualdades sociais.

A autora nos leva ao nascimento do Estado-Nação, afirmando que "o modelo de escola e de cultura escolar que ainda hoje é hegemônico em nossa sociedade surge com o nascimento do Estado-Nação", mas não apenas nele, surge também a partir da "necessidade de se ter uma única cultura circunscrita a um único território". Para conquistar tais ideais Leite (2015) nos mostra que o exército e a escola foram fundamentais.

O exército cumpriu sua função de dominar e, inclusive, dizimar grupos que não aceitavam se submeter a um poder único. [...] A constituição do Estado-Nação exigiu, dessa forma, a homogeneização de uma sociedade até então bastante heterogênea, sobretudo em sua dimensão cultural. Para isso, a escola cumpriu um papel fundamental, criando uma cultura comum que deveria ser compartilhada por todos os cidadãos, já que havia a exigência de se ter, no território, uma única língua, uma única identidade (Leite, 2015, p. 15).

O que autora nos mostra no decorre de seu texto é um caminho trilhado pela escola tomando por base a imposição da cultura dos grupos dominantes, deixando a margem outros perfis de cidadãos, negros, 
camponeses, indígenas e claro os pobres. E foram esses sujeitos que ficaram a margem que passaram a questionar esse modelo de escola, que em tese seria "igual para todos", mas que na prática estabelecia relação apenas com um grupo específico.

Afinal o que então a escola pode fazer? Quando falamos em educação e pobreza estamos lutando por uma educação que esteja atenta as demandas sociais, que em seu currículo estejam incorporadas essas realidades postas no espaço social, que ela dialogue com as diferentes subjetividades, ou seja, uma escola que seja comprometida com a transformação social.

O que se espera é que a escola consiga romper com seu status quo, que ao invés de adaptar todo mundo ao mesmo padrão oportunize espaços onde as diferenças sejam bem vindas e valorizadas, que trabalhe na perspectiva de transformação da vida dos sujeitos, que eduque para a vida e para além dela. Que seja ofertado um conhecimento que estabeleça relação de significado com a vida de seus alunos, uma escola que dê centralidade aos sujeitos, no plural, e não apenas ao sujeito da classe dominante. Uma escola que rompa com o discurso da meritocracia e que não se abstenha de sua função social.

Uma educação voltada para as demandas da pobreza é uma educação que não desconsidere a bagagem cultural de seus alunos, que não trabalhe na perspectiva que os alunos que cheguem a ela se encaixem a um modelo que não faz relação alguma com suas experiências sociais. A esse respeito Leite (2015) nos alerta que:

[...] considerar os sujeitos no centro do processo educativo implica muito mais que colocar a formação de sujeitos críticos e participativos como um dos objetivos do Projeto Político Pedagógico da escola. Considerá-los no centro do processo educativo acarreta reorganizar tempos, espaços, agrupamentos, conteúdos escolares. Importa também em mudar o lugar dos educandos/as e educadores/as na dinâmica do trabalho e, principalmente, em transformar a vida da escola, entendendo-a como espaço de cultura (Leite, 2015, p. 20).

Diante do exposto fica a indagação a respeito do currículo escolar e como ele tem dialogado com as questões da pobreza, para além disso: como o pobre se vê, em que medida ele associa a responsabilidade por sua condição de pobreza? Em termos de currículo Arroyo (2015, p. 17) nos adverte que "os saberes ali contemplados são entendidos como a única forma de pensar válida, a única cultura nobre, a única racionalidade", logo não existe nenhum sentimento de pertença dos pobres com essa forma de pensar, é como se a escola falasse de um outro mundo, que diante de muitos entraves torna-se inacessível, exceto pela promessa amplamente divulgada, afinal se esses saberes forem aprendidos, "inexoravelmente levarão a humanidade ao progresso".

Essa visão acaba gerando a ideia de que os que estão em condição de vulnerabilidade social, estariam inseridos nessa realidade por não tomarem posse desses saberes científicos, que ainda nas palavras de Arroyo (2015, p. 17) são "supostamente emancipadores". Ao versar sobre “o direito a saber-se pobre”, Arroyo (2015) afirma que:

O primeiro conhecimento a que todo ser humano tem direito é compreender-se no mundo, na sociedade, na história. O saber-se pobre é o discernimento mais persistente nas vidas, no passado e presente das famílias e comunidade empobrecidas. Se esse é o saber mais premente, o direito a ser garantido, na escola e nos currículos, não será a conhecimentos que aprofundem, sistematizem, alarguem esse saber-se pobre? [...] Contudo, os currículos assumem apenas a 
responsabilidade de oferecer aos/às alunos/as os conhecimentos acumulados sobre a natureza, a sociedade, o espaço, a história, a linguagem etc., e têm ignorado e secundarizado o direito a saber de si, ao saber-se no mundo, na sociedade, na natureza, nas relações sociais, econômicas e políticas, no padrão de trabalho, de produção, de apropriação-segregação do espaço da terra e da renda. Conhecer-se nesses padrões sociais e políticos que os condicionam como pobres ao longo da história é a síntese do seu direito ao conhecimento que a escola, a docência, os currículos têm o dever de garantir-lhes (Arroyo, 2015 p. 19-20).

De fato, existem dois modelos de escola, duas formas de se educar e isso acaba por servir como ferramenta de manutenção da pobreza. Santos (2018, p. 33) nos fala sobre essas duas faces da educação. Para a autora existe uma escola para os pobres e outra para as classes dominantes. Dessa forma a escola para os pobres oferece "uma educação que garante minimamente o conhecimento necessário para o domínio das habilidades indispensáveis ao trabalho produtivo", ou seja, condição necessária para manutenção das regalias da elite. Já a escola da classe dominante "prepara seus descendentes para o comando, para ocupar os melhores cargos e perpetuarem a posse dos bens".

Na mesma direção Brito, Arruda \& Contreiras (2015, p. 18677) nos falam sobre essa dualidade que perpassa o seio escolar, para os autores "todos têm a mesma capacidade de aprender, o que interfere são as condições sociais para esta aprendizagem, o contexto em que o indivíduo se encontra e sua realidade". É injusto esperar que uma criança pobre que não tem acesso aos mesmos recursos que a criança das elites se desenvolva da mesma forma que está última, existe uma desigualdade gritante e é tarefa da escola acertar essas arestas, pois embora as realidades sejam distintas isso não impede que a criança pobre possa aprender o mesmo conteúdo, e é nesse sentido que os autores tecem a crítica a dualidade de conhecimentos ofertado pela escola, ainda nas palavras dos autores, “ a educação vem falhando, perpetuando a "escola para pobre" e "escola para elite".

Cabe aqui frisar que a premissa desse trabalho não é a de desacreditar a escola, ou vê-la como instituição fadada ao fracasso, muito pelo contrário, acredito na escola como instrumento de transformação social, uma escola que se pretenda democrática e igualitária.

Uma escola compreendida enquanto espaço privilegiado da transformação social e que deve buscar a conscientização e formação dos sujeitos, ou seja, formá-los na perspectiva da criticidade e consciência de sua realidade no mundo, não preso a visões fatalistas, como se sua situação não pudesse ser mudada, tampouco numa visão utópica como se a educação fosse a panaceia da pobreza, vendo-a mesmo como possibilidade da realidade que se tem e a partir disso que caminhos são possíveis serem trilhados. Grosso modo o que se espera é uma escola que eduque na perspectiva da transformação social, oportunizando ao sujeito a consciência de quem se é no mundo.

Uma escola justa e democrática deve formar um sujeito crítico e consciente de sua realidade, apontando caminhos para que este possa intervir, mudar ou superar as condições adversas, criando possibilidades na busca das condições necessárias para uma vida digna (Brito; Arruda \& Contreras, 2015, p. 18677).

Temos na contemporaneidade a presença de sujeitos que mesmo marginalizados conseguiram ingressar no ensino superior, e isso é fruto da instituição escolar. O pobre tem chegado à universidade, não só ele, mas o negro, o índio, aqueles que antes nem sonhavam com tal realidade. É também sobre essa escola que estamos 
falando, é nesse espaço educativo que esses sujeitos conseguem ter acesso ao conhecimento, dito de outro modo, o que podemos perceber é que sim, a escola tem avançado em alguns aspectos.

A discussão aqui proposta é justamente para que caminhos de diálogos e reflexão sejam propostos e oportunizados. Podemos ainda não ter a escola dos sonhos, mas talvez a pergunta mais pertinente seja: O que podemos fazer a partir da escola que temos? Que ferramentas ou que políticas públicas têm sido criadas para deixarem o viver em sociedade mais igualitários?

Brito, Arruda \& Contreras (2015, p. 18674) afirmam que "a educação se dá em diferentes espaços e a escola é um das quais crianças pobres, têm mais acesso, sendo está a principal forma de educação". A partir disso ressalto a importância do espaço educacional como lugar da transformação social. Nossos jovens pobres têm chegado as universidades, a exemplo disso podemos citar a política de cotas das universidades públicas, que visa garantir o acesso a estudantes ao ensino superior por meio de ações afirmativas, que se tratam de um conjunto de medidas especiais voltadas a grupos discriminados ou excluídos socialmente em tempos antigos ou atuais.

Podemos na contemporaneidade ver a presença de atores sociais nos cursos superiores, o que outrora antes era inalcançável, devido as condições sociais. Essas medidas postas para amenizar as desigualdades sociais só são possíveis, graças a instituição primeira de ensino, a escola, como apontada acima a principal forma de educação de crianças pobres.

Em contrapartida Cislaghi et al. (2019) nos adverte que:

A mercantilização do ensino básico, o desfinanciamento das universidades públicas, a estigmatização das mesmas como espaços de "balbúrdia" e de saber ideologizado são amostras concretas do atual projeto de governo de Bolsonaro. Na defesa deste viés, o governo condena a liberdade de expressão, o ensino crítico e o projeto de uma educação pública, gratuita e para todos, dificultando possibilidades de organização e mobilização desses setores (Cislaghi et al. 2019, p. 6).

Estamos vivenciando um momento preocupante para a educação, com desmontes de políticas públicas, diminuição/corte de verbas para a educação, sobretudo nas ciências humanas e isso afeta diretamente a educação que é a ofertada a população, principalmente a população pobre do nosso país. São períodos de retrocessos e sobretudo de lutas que precisam ser mantidas para quem sabe amenizar o estrago que o impacto dessas ações poderá acarretar para a educação ao longo dos anos.

\section{CONSIDERAÇÕES FINAIS}

No decorrer deste estudo foi possível observar como popularmente se naturalizou o conceito de pobreza e como se faz necessário se desnaturalizar definições e visões moralizantes sobre aqueles que vivem em situação de vulnerabilidade social. Refletir acerca da relação entre educação e pobreza nos leva a perceber como elas estão juntas e como tem caminhado lado a lado no decorrer dos anos, seja sendo silenciada, maquiada, justificada, ou denunciada, refletida, dialogada. No decorrer deste trabalho refletimos sobre pobreza e educação 
e nesse sentido analisamos a escola e sua função social, desta forma foi observado o processo de construçãohistórico social da pobreza, e foi possível perceber que a pobreza tem história, ela é fruto de relações sociais desiguais e injustas que vem se perpetuando no decorrer do tempo.

A partir da leitura dos autores aqui citados no decorrer de todo o texto foi possível perceber a urgência de refletir sobre a escola que temos e que sujeitos ela tem formado. Neste sentido, desenvolvemos uma crítica a respeito de como a escola tem desenvolvido seu trabalho em relação à pobreza. Nessa crítica reconhecemos práticas e políticas de enfrentamento da pobreza, mas, também, identificamos situações em que esta mesma escola acabou desenvolvendo processos de exclusão.

A população pobre ou extremamente pobre ainda é um fato em nosso país. Muitas pessoas nem têm noção da situação em quem vivem, cresceram embaladas na melodia do "Deus quis assim". Romper com essa cultura que oculta com eufemismos as verdadeiras causas da pobreza é uma tarefa necessária a ser assumida pela escola e que todos/as educadores/as devem estar atentos.

O exercício de escrever um texto acadêmico sobre essa temática em meio a uma pandemia nos deixou ainda mais próximos do problema. Foi doloroso perceber como a pobreza se mostrou ainda mais evidente e de forma mais gritante em nosso contexto social, quando tivemos a oportunidade de encontrar famílias que não tinham o que comer, tampouco onde buscar.

É necessário descontruir os discursos de que a pobreza fosse um fenômeno natural. Muitos desses discursos servem apenas para a manutenção de um controle de corpos de seres humanos que vivem nos limites, no limite de não ter comida, no limite de não ter saúde, no limite de não ter educação, moradia, de não ter uma vida digna como assegurada no campo teórico da Constituição Federal (1988).

Não existe outro caminho senão o de uma educação emancipadora que oportunize a transformação social, caso contrário permaneceremos na mesmice de dias que se seguem sem que mudanças cheguem as grandes massas de nossa população.

A visão moralizante de pobreza enaltece a meritocracia, a usando como muleta para fortalecer seus discursos que culpabilizam aqueles que se encontram na marginalidade social. É apenas uma forma do Estado se omitir de suas obrigações para com a sociedade e assim ter como forma de reserva um grupo de cidadãos que trabalham muito, ganham pouco e não reclamam de sua situação, no mínimo se sentirão culpados.

O fato é que as subjetividades não são as mesmas e antes de falarmos sobre méritos individuais é preciso que reflitamos sobre o contexto histórico, sobre como vivem essas pessoas, que memórias, que experiências e acima de tudo, que oportunidades tiveram. Que tipo de educação lhes foi ofertada? Foram formados para o mundo das ideias ou para (e unicamente) o mercado de trabalho?

A pesquisa nos levou por diversos momentos históricos, e os autores nos ajudaram a perceber a anormalidade da pobreza, no sentido de que é preciso criar uma estranheza ao que popularmente se naturalizou. A pobreza, por fim, não é natural, mas produção social, injusta. 
Nesta perspectiva, foi fundamental a reflexão desenvolvida por Arroyo (2015) ao defender a urgência e necessária revisão do que popularmente entendemos por pobreza, sobretudo quando a olhamos sob a ótica da meritocracia, o autor vai nos levar então a repensarmos as visões moralizantes da pobreza na perspectiva de compreendê-las enquanto fruto de relações sociais que vem se perpetuando no percurso histórico.

Leite (2015) nos traz uma reflexão necessária a respeito dos que vivem nos limites da sobrevivência, apresentando que mesmo amparados pela mesma legislação crianças e jovens tem acesso diferenciado aos direitos e deveres que lhes são assegurados, e esse diferencial para muitos se materializa no campo da desigualdade lhes falta saúde, educação, lhes falta o mínimo para viver dignamente.

Em relação à escola, foi possível perceber que temos avanços consideráveis no campo social, e eles foram possíveis graças a instituição escolar. Entretanto podemos notar que a escola ainda pode fazer mais, repensar seus currículos se mostrou como uma primeira ação necessária, na perspectiva de que a escola reflita que sujeitos tem formado e para que. É urgente formá-los para a transformação social e essa transformação começa na escola, com acesso a conhecimento e educação de qualidade.

Diante de todas essas teorias, é possível afirmar que a função social da escola pública brasileira em relação à pobreza é promover o acesso à educação de qualidade para todos, na perspectiva da transformação social, extrapolando a educação que apenas mantem o status quo vigente, - onde temos uma escola para pobre, outra para rico. A função social da escola é construir caminhos possíveis para que crianças e jovens tenham acesso de fato a uma educação emancipadora. É função social da escola pública brasileira formar sujeitos críticos e conscientes de sua realidade.

\section{Conflitos de interesses}

O autor declara que não há conflitos de interesse. O autor está ciente da submissão do artigo.

\section{REFERÊNCIAS}

Arroyo, M. G. (2015). Pobreza, desigualdades e educação. Módulo Introdutório. Curso de Especialização em Educação, pobreza e desigualdade social. Brasília - DF: MEC.

Bello, S. F.; Hayashi, M. C. P. I., Silva, R. C. \& Pizzani, L. (2012). A arte da pesquisa bibliográfica na busca do conhecimento. Revista Digital de Biblioteconomia e Ciência da Informação. Campinas - SP.

Brasil (1988). Constituição Federal de 1988. Constituição da República Federativa do Brasil. https://www.planalto.gov.br/ccivil 03/constituicao/constituicao.htm

Brasil (1990). Estatuto da Criança e do Adolescente (ECA). Lei no 8.069, de 13 de julho de 1990. http://www.planalto.gov.br/ccivil 03/leis/18069.htm

Brasil (2015). Atlas da vulnerabilidade social dos munícipios brasileiros. Instituto de Pesquisa e Econômica Aplicada IPEA. Brasília. 
Brito, M. H. P.; Arruda, N. A. O. \& Contreras, H. S. H. (2015) Escola, pobreza e aprendizagem: reflexões sobre a educabilidade. EDUCERE, XII Congresso Nacional de Educação. https://educere.bruc.com.br/arquivo/pdf2015/21930 10055.pdf

Carmo, M. E. \& Guizardi, F. L. (2017). O conceito de vulnerabilidade e seus sentidos para as políticas públicas de saúde e assistência social. Cadernos de Saúde Pública. https://www.scielo.br/pdf/csp/v34n3/1678-4464-csp-34-03e00101417.pdf

Cislaghi, J. F.; Cruz, J. B.; Santos, M. C. C.; Mendonça, T. S. \& Ferreira, F. G. Não é uma crise, é um projeto: a política de educação do governo Bolsonaro. $16^{\circ}$ Congresso Brasileiro de Assistentes Sociais. https://broseguini.bonino.com.br/ojs/index.php/CBAS/article/view/764/744

Duarte, N. S. (2012) Política Social: um estudo sobre educação e pobreza. 260 f. Tese (Doutorado em Política Social) - Universidade de Brasília, Brasília. https://repositorio.unb.br/handle/10482/10909

Freire, P. (2019) Pedagogia do Oprimido. 68 ed. São Paulo: Paz e Terra.

Guimarães, V. O. S. (2016) Construção histórico-social da pobreza: desnaturalização da percepção das desigualdades sociais. Científic@-Multidisciplinary Journal, Anápolis - GO.

http://periodicos.unievangelica.edu.br/index.php/cientifica/article/view/1921

Leite, L. H. A. (2015) Escola: Espaços e Tempos de Reprodução e Resistência da Pobreza. Módulo I. Curso de Especialização em Educação, pobreza e Desigualdade Social. Brasília - DF: MEC.

Medeiros, J. B. (2012) Redação científica: a prática de fichamentos, resumos, resenhas. 11 ed. São Paulo: Atlas.

Schwartzman, S. (2004) As Causas da Pobreza.

https://www.researchgate.net/profile/Simon Schwartzman/publication/224771519 As causas da pobreza/li nks/5be1b73d4585150b2ba2e506/As-causas-da-pobreza.pdf

Rocha, S. (2003) Pobreza no Brasil: afinal, de que se trata? Rio de Janeiro: FGV.

Santos, Z. M. M. L. (2017) Escola como espaço de transformação: a articulação da educação, pobreza e desigualdade social no currículo escolar. Revista Internacional de Investigación en Ciencias Sociales. http://scielo.iics.una.py/pdf/riics/v13n2/2226-4000-riics-13-02-00239.pdf

Santos, M. E. M. (2018) Relações históricas entre trabalho, educação e pobreza. Teresina: EDUFPI.

Silva S. B. \& Rapoport, A. (2020). Desempenho escolar de crianças em situações de vulnerabilidade social. Revista Educação em Rede: formação e prática docente. v. 2, 2013.

http://ojs.cesuca.edu.br/index.php/educacaoemrede/article/view/410

Silva, T. T. (2013) Documentos de identidade: uma introdução às teorias do currículo. 3. ed. Belo Horizonte: Autêntica, 2013.

Trisotto, F. (2020) Décadas de retrocesso: como a Covid-19 vai ampliar a pobreza e a desigualdade no país. https://www.gazetadopovo.com.br/republica/pobreza-desigualdade-social-brasil-covid-19/ 